\title{
Avaliação do tratamento de pacientes submetidos a osteogênese por distração na tíbia*
}

\section{Evaluation of the Treatment of Patients Subjected to Osteogenesis Induced by Tibia Bone Distraction}

\author{
Henrique Carvalho de Resende ${ }^{1}$ Diogo de Vasconcelos Sabido Gomes ${ }^{2}$ \\ Gabriel Milhomem da Silva Mota ${ }^{2}$ \\ ${ }^{1}$ Núcleo de Ortopedia e Traumatologia, Lourdes, Belo Horizonte, MG, Brasil \\ ${ }^{2}$ Hospital Maria Amélia Lins (HMAL), Belo Horizonte, MG, Brasil \\ Endereço para correspondência Gabriel Milhomem da Silva Mota, \\ Hospital Maria Amélia Lins (HMAL), Rua dos Otoni, 772, Santa Efigênia, \\ Rev Bras Ortop 2020;55(1):75-81. \\ Belo Horizonte, MG 30150-270, Brasil \\ (e-mail: gabrielmsmota@hotmail.com).
}

\section{Resumo}

\section{Palavras-Chave}

- infecção óssea

- regeneração óssea

- osteogênese

- distração óssea

- técnica de ilizarov

- tíbia

\begin{abstract}
Trabalho feito no Hospital Maria Amélia Lins (HMAL), Belo Horizonte, MG, Brasil.
\end{abstract}

Objetivo Avaliar o tratamento das fraturas de tíbia que evoluíram com perda óssea (traumática ou secundária a infecção) e as complicações ocorridas durante o tratamento com fixador externo e no período imediatamente após sua retirada.

Métodos Foram selecionados 40 pacientes tratados entre 2010 e 2017, com a idade média de 33,02 anos, sendo 34 do sexo masculino e 6 do sexo feminino. Todos os pacientes portavam regenerado ósseo da tíbia, foram vítimas de trauma (sobretudo motociclístico), e estavam em seguimento ambulatorial.

Resultados Foram obtidos regenerados ósseos da tíbia proximal de até $17 \mathrm{~cm}$ e da tíbia distal de $14 \mathrm{~cm}$. O maior transporte trifocal teve a soma do tamanho dos tecidos dos ossos regenerados, medindo $14,5 \mathrm{~cm}$. Como complicações, 29 (72,5\%) pacientes tiveram infecção no trajeto dos pinos e fios. Houve $9(22,5 \%)$ casos de refratura, sendo 6 deles tratadas com novo fixador circular, e 2 infecções no osso regenerado. Os pacientes foram submetidos a uma média de 4,72 procedimentos cirúrgicos (2-12), portaram fixador por 20,75 meses (7-55 m.) e permaneceram internados por 53,7 dias (5-183) devido principalmente a complicações de partes moles, a antibioticoterapia intravenosa ou até mesmo a questões sociais. Dois (5\%) pacientes apresentaram gonartrose sintomática e outros 2 artrite sintomática do tornozelo. Três apresentaram discrepância de membros inferiores de 3,0; 3,7 ; e $5,0 \mathrm{~cm}$.

Conclusão Apesar de não ser um método de tratamento amplamente disponível, o método de llizarov é útil para solucionar a maioria das falhas ósseas da tíbia, independente da sua etiologia.

Objectives Evaluation of the management of tibial fractures that resulted in bone loss (traumatic or resulting from infection) and the complications that occurred during the treatment with external fixator and immediately after its withdrawal. recebido

11 de Maio de 2018

aceito

27 de Novembro de 2018
DOI https://doi.org/

10.1055/s-0039-1700819. ISSN 0102-3616.
Copyright $\odot 2020$ by Sociedade Brasileira License terms de Ortopedia e Traumatologia. Published by Thieme Revinter Publicações Ltda, Rio de Janeiro, Brazil 


\author{
Keywords \\ - bone infection \\ - bone regeneration \\ - osteogenesis \\ - bone distraction \\ - ilizarov technique \\ - tibia
}

\begin{abstract}
Methods Forty patients were selected from 2010 to 2017. The mean age of the patients was 33.02 years; 34 subjects were male and 6 were female. All patients had tibial bone regeneration, suffered trauma -(mainly related to motorcycle accident) and were followed-up at an outpatient facility.

Results Proximal tibial bones of up to $17 \mathrm{~cm}$ in length and distal tibial bones of up to $14 \mathrm{~cm}$ in length were obtained. The biggest trifocal transport had the same length as that of regenerated bone tissues, which was $14.5 \mathrm{~cm}$. Regarding complications, 29 (72.5\%) patients had infections in the pin and wire paths. There were $9(22.5 \%)$ cases of de novo fracture, 6 of which were managed with the implantation of a new circular fixator, and 2 cases of infection of the regenerated bone. The patients were subjected to 4.72 procedures on average (2-12), held the fixator for 20.75 months (7-55 months) and stayed in the hospital for 53.7 days (5-183 days), mainly because of complications in soft tissues, intravenous antibacterial therapy and even social issues. Two (5\%) patients presented with symptomatic gonarthrosis and 2 other patients had symptomatic ankle arthritis. Three of the patients showed lower limb discrepancy of 3.0,3.7, and $5.0 \mathrm{~cm}$.

Conclusion Despite not being widely available, the llizarov method is useful for solving the majority of tibial bone losses, regardless of their etiology.
\end{abstract}

\section{Introdução}

A falha óssea, seja qual for sua causa, tem no método de Ilizarov um alto índice de sucesso. ${ }^{1}$ Seu uso permite o tratamento simultâneo da pseudartrose, de grandes falhas ósseas, encurtamento, deformidades, e infecção, ${ }^{1-3}$ sem parte das limitações impostas por outras técnicas, como as desenvolvidas por Papineau ${ }^{4,5}$ e Masquelet. ${ }^{6}$

A produção de um regenerado ósseo de qualidade é de suma importância, e uma corticotomia subperióstica que proteja os elementos osteogenéticos e que visa obter a neovasculogênese e consequente neoformação óssea tem o seu papel bem solidificado na literatura. ${ }^{1,7,8}$ O processo de calotaxia gera um aumento importante da circulação sanguínea no membro, ${ }^{8-10}$ proporcionando um ambiente propício para a resolução de quadros infecciosos, fechamento de feridas e consolidação óssea.

A ressecção óssea no caso das pseudartroses infectadas deve ser a mais agressiva possível, com excisão oncológica de todo o segmento ósseo acometido, para que o tratamento se mostre bem sucedido e sem complicações ou recidivas. ${ }^{1,3,9,10}$ O segmento remanescente deve apresentar sangramento ativo, sendo esse um importante sinal de viabilidade. ${ }^{8}$

Os processos de transporte e alongamento ósseo têm uma incidência esperada de complicações, como infecção do regenerado ósseo, ausência de consolidação no foco do docking, ausência de formação óssea no segmento regenerado, consolidação precoce da corticotomia, refraturas, lesões vasculares, dentre outras. ${ }^{9}$ Outras complicações têm uma relação mais direta com o trauma inicial, como a artrite secundária das articulações adjacentes. ${ }^{11}$

Visamos relatar e avaliar aspectos epidemiológicos, o tratamento e as complicações das fraturas de tíbia que necessitaram da produção de regenerados ósseos através do método de Ilizarov.

\section{Materiais e Métodos}

O presente estudo de caráter retrospectivo foi aprovado pelo comitê de ética da instituição proponente com o certificado de apresentação e apreciação médica (CAAE) n. 78498817.1.00 00.5119, e n. do parecer: 2.322.439. O estudo incluiu 40 pacientes submetidos a consulta médica especializada entre 17 de dezembro de 2016 e 17 de junho de 2017 e que foram submetidos previamente a fixação externa circular com aparelho de Ilizarov de aço. A população do estudo foi composta apenas por indivíduos submetidos a alongamento ou transporte ósseo na tíbia, com um número total de 40 indivíduos. Foi um critério de inclusão a remoção prévia do fixador externo. Toda a nossa população foi vítima de trauma.

A técnica usada foi a estabilização do segmento associada ao alongamento ou transporte ósseo bifocal ou trifocal, de acordo com a necessidade de cada caso. 0 transporte trifocal tem como vantagem proporcionar a neoformação óssea a partir de dois focos, o que reduz o tempo total de tratamento. ${ }^{12} \mathrm{~A}$ corticotomia foi executada com serra de Gigli ou a partir de pré-perfurações com broca e complementação com formões. 0 ritmo da produção do regenerado ósseo foi de 0,5 a $1 \mathrm{~mm} / \mathrm{dia}$, a depender da qualidade do regenerado ósseo produzido. 0 docking dos fragmentos principais foi realizado em bloco cirúrgico, após a revitalização das bordas dos fragmentos e visualização de sangramento ativo. ${ }^{3}$ Após essa etapa e o término do alongamento, os pacientes foram submetidos a dinamização do aparelho com o afrouxamento de uma ou duas barras rosqueadas, de um total de quatro. A retirada do fixador foi baseada em radiografias em pelo menos três incidências evidenciando consolidação óssea. Após essa etapa, os pacientes receberam um tutor de polipropileno, que foi utilizado atéo término da fase de remodelação óssea.

Foram excluídos três pacientes devido à falta de dados no prontuário, e incluída uma paciente que retirou o fixador 
após a coleta de dados do presente trabalho devido a relevância do caso.

\section{Resultados}

O mecanismo do trauma predominante foi acidente de motocicleta, sendo a causa base de 26 pacientes (65\%). No caso de 9 (22,5\%) pacientes, houve colisão com carro, em 3(7,5\%), colisão com ônibus ou com outra motocicleta, e em 2 (5\%), ocorreu queda simples da motocicleta. Houve $1(2,5 \%)$ caso de colisão contra caminhão, e 8 (20\%) de acidentes de motocicleta não especificados. Seis pacientes (15\%) foram vítimas de atropelamento, sendo $3(7,5 \%)$ atropelados por caminhão, dos quais 1 foi após queda da bicicleta. Outro $(2,5 \%)$ paciente foi atropelado por um automóvel, e 2 (5\%) sofreram atropelamento não especificado. Outros 4 (10\%) foram vítimas de queda de altura e 4 (10\%) sofreram acidente automotivo não especificado.

O gênero mais acometido foi o masculino, com 34 (85\%) indivíduos. A média de idade, na ocasião do trauma, era de 33,02 anos, com a mediana em 32,5 anos (12 a 51a.). As 6 (15\%) pessoas do gênero feminino tinham idade média de 27,5 anos, e mediana de 24,5 (9 a 52). O lado mais acometido foi o direito (21 casos ou 52,5\%).

As lesões primárias foram fraturas diafisárias da tíbia em $34(85 \%)$ casos, 2 (5\%) do platô e $4(10 \%)$ do pilão. No subgrupo das diafisárias, 10 (25\%) foram classificadas na urgência como AO42C3 e 2 (5\%) AO42C2. Houve uma (2,5\%) de cada a seguir: A042B3, A042B2, AO42B1 e A042A2. Apenas duas fraturas foram sabidamente fechadas. As expostas foram classificadas pelo sistema de Gustilo como 1 (2,5\%) tipo G2, 9 (22,5\%) G3A, 5 (12,5\%) G3B, e 2 (5\%) G3C. Dois pacientes (5\%) apresentaram déficit neurológico local. Vinte (50\%) foram sabidamente submetidos a desbridamentos, rotação de retalho ou enxerto de pele pela equipe de cirurgia plástica antes da montagem do fixador externo.

No tocante às lesões associadas, em $11(27,5 \%)$ casos, houve joelhos flutuantes, sendo $7(17,5 \%)$ às custas de fraturas da diáfise femoral, uma do côndilo medial, outra do femur distal (AO 33C3), outra epifisiólise do femur distal (Salter Harris II) e outra fratura não especificada do fêmur distal da criança. Houve três casos de luxação do joelho e uma lesão isolada do ligamento cruzado anterior (LCA). Houve 1 (2,5\%) caso dos seguintes: fratura de pododáctilo, cuboide, maléolo medial, calcâneo e amputação traumática do $5^{\circ}$ pododáctilo. Houve 2 (5\%) casos de fratura bilateral da tíbia, sendo um deles em um joelho flutuante. Dois pacientes (5\%) apresentaram fratura da coluna lombar, 1 (2,5\%) luxação occipitocervical com fratura do condilo occipital e outro com fratura da coluna não especificada. Lesões associadas de bacia afetaram um (2,5\%) indivíduo, na forma de fratura dos ramos púbicos. Já as lesões de membros superiores foram mais prevalentes, com três $(7,5 \%)$ casos de fratura de falanges e $1(2,5 \%)$ caso de cada a seguir: diáfise do úmero, rádio distal, $2^{\circ}$ metacarpo, $5^{\circ}$ metacarpo, mallet finger, escafoide e lesão do plexo braquial.

Dois subgrupos de pacientes foram criados, sendo um composto pelos que foram submetidos a alongamento, com 18 membros, e outro com os 22 restantes submetidos a transporte ósseo.

\section{Alongamento}

A causa base do alongamento foi, para 11 (61,1\%) indivíduos a pseudartrose infectada e para $3(16,6 \%)$, a falha óssea aguda pós traumática. Para outros 4 (22,2\%) indivíduos, o alongamento foi realizado para correção de encurtamento, sendo gerados na correção de deformidade, após a ressecção do tálus e debridamentos e na ressecção de osso infectado na tíbia. Um deles teve a causa de encurtamento não informada no prontuário.

Quinze $(83,3 \%)$ pacientes foram submetidos a corticotomia em região de metáfise proximal da tíbia, sendo a produção do regenerado proximal ao foco do docking. 0 tamanho médio do mesmo foi de $5,46 \mathrm{~cm}$, com uma mediana de $5,5 \mathrm{~cm}$ (1,8 a 9 centímetros). Dois $(11,1 \%)$ foram submetidos a corticotomia em metáfise distal da tibia, distal ao foco do docking. Estes portam regenerados de 3,5 e 7,5 cm. Houve um caso de transporte trifocal in tandem, sendo ambas as corticotomias proximais ao foco do docking. Os regenerados produzidos medem $3,5 \mathrm{~cm}$ e $4,5 \mathrm{~cm}$, de proximal para distal. Doze, ou $66,6 \%$, foram submetidos a fibulectomia.

Durante a calotaxia, foi necessário o acordeonamento do regenerado de dois pacientes devido a má qualidade óssea. Um outro teve o seu alongamento pausado por um tempo e depois retomado, e um outro, que alongou a uma velocidade muito superior à orientada, foi submetido a marcha-a-ré de $15 \mathrm{~mm}$.

Ainda a respeito dos regenerados, um evoluiu com recurvato e outro com flexão, sendo o último submetido a correção em bloco cirúrgico. Houve ainda o caso de um paciente que manipulou o fixador por conta própria, prejudicando o alinhamento do membro como um todo, sendo necessária reabordagem cirúrgica.

Onze $(61,1 \%)$ indivíduos tiveram em algum momento do tratamento infecção em trajeto de fio ou pinos, e $2(11,1 \%)$ tiveram relato de sequestro ósseo. Houve uma retirada de espícula óssea do subcutâneo em bloco cirúrgico e uma reabordagem devido a exposição óssea. Um paciente foi submetido a troca dos fios do componente podálico devido a dor e outro teve o fio retirado devido a formação de abscesso em seu trajeto. Também houve a drenagem de um abscesso em coxa e de uma artrite séptica de tornozelo.

Quatro (22,2\%) indivíduos sofreram refratura, sendo que em apenas um caso foi necessária a confecção de um novo fixador circular devido a refratura ao nível da artrodese do tornozelo. Outro sofreu refratura no foco da pseudartrose, sendo submetido a tratamento conservador com o uso do tutor e restrição de carga. Outro teve uma refratura exposta, sendo submetido a desbridamento e a fixação monoplanar na urgência, que acabou se tornando o tratamento definitivo. Por fim, também ocorreu uma refratura no foco do regenerado, tratada conservadoramente.

Após a retirada do fixador, há o relato de um paciente com gonartrose grave, outro com osteoartrite sintomática do tornozelo, 2 com rigidez do joelho, 1 com dedos em garra, outro com encurtamento residual de $5 \mathrm{~cm}$, e outro com flexo residual de $15^{\circ}$.

A quantidade total de abordagens cirúrgicas foi de de 65 para os 18 pacientes, variando entre 2 e 7 , tendo como média 
3,61 abordagens e mediana de 3. Os pacientes permaneceram internados por 637 dias, variando entre 10 e 79 dias, tendo como média 35,38 dias e mediana de 31 dias. 0 tempo total de uso do fixador externo foi de 280 meses completos, variando entre 7 e 37 meses, tendo como tempo médio 15,55 meses e mediana de 12 .

\section{Transporte}

Dos 22 pacientes submetidos a transporte ósseo, em 12 $(54,5 \%)$ a causa foi a falha óssea gerada após a ressecção do foco de pseudartrose infectada, $9(40,9 \%)$ apresentaram falha óssea aguda pós-traumática (-Figura 1), e 1 (4,5\%) por motivo não informado.

Onze (50\%) foram submetidos a uma corticotomia em região de metáfise proximal da tíbia (-Figura 2 ). 0 regenerado produzido teve o tamanho médio de $8,53 \mathrm{~cm}$, variando entre 4 e $17 \mathrm{~cm}$ (-Figura 3), com uma mediana de $8 \mathrm{~cm}$. Houve um $(4,5 \%)$ caso de uma corticotomia distal ao foco do docking, que deu origem a um regenerado de $14 \mathrm{~cm}$. Em $4(18,1 \%)$ casos, houveram duas corticotomias, sendo uma proximal e outra distal ao foco de compressão ( - Tabela 1 ). 0 tamanho médio do regenerado proximal foi de $5 \mathrm{~cm}$ e o do distal de $5,6 \mathrm{~cm}$. Em outros $4(18,1 \%)$ pacientes, foi realizado o transporte trifocal in tandem, onde ambos os regenerados se localizavam proximais ao foco do docking e mediam em média $3,8 \mathrm{~cm}$ e $3,67 \mathrm{~cm}$, de proximal para distal. Por fim, houve 2 ( $9 \%$ ) casos em que foram realizados transportes trifocais sequenciais, mas com o foco de compressão proximal aos focos do alongamento, medindo 2,5 e $3,8 \mathrm{~cm}$ (regenerados proximais) e 12 e $3 \mathrm{~cm}$ (regenerados distais). Quinze $(68,1 \%)$ foram submetidos a fibulectomia.

Ocorreram dois casos de infecção no foco do regenerado. Em um deles, foi tentado debelar a infecção cirurgicamente e mantido espaçador de cimento em uma tentativa de se realizar a tecnica de Masquelet, sem sucesso. No outro, foi administrado antibióticos por longos períodos e realizado desbridamentos, sendo aceitada a discrepância final de $3 \mathrm{~cm}$ e interrompido o alongamento.

Durante a fase de neoformação óssea, ocorreu a consolidação precoce da corticotomia em $4(18,1 \%)$ casos, sendo essa refeita. Ocorreu 2 caso de pausa no transporte devido a produção de regenerado pobre, e 2 casos de marcha-a-ré, sendo uma não especificada e outra de $5 \mathrm{~mm}$.

Dezoito (81\%) casos tiveram em algum momento do tratamento infecção em trajeto de fio ou pinos, e $4(18,1 \%)$ tiveram relatado seqüestro ósseo. Em 2 casos, os pacientes foram levados ao bloco cirúrgico para retirada de espícula óssea exposta, 3 (13,6\%) para debridamento e outros 2 (9\%) para enxertia de pele devido a falta de cobertura cutânea no foco do docking. Ainda teve um caso de montagem de componente podálico devido a pé em equino, que recidivou. Também ocorreu uma deformidade em varo do tornozelo durante o tratamento, sendo realizada correção ambulatorial.

Cinco pacientes (22,7\%) sofreram refratura. Três delas (13,6\%) ocorreram no foco do docking da tíbia, sendo duas durante a fisioterapia. As outras 2 (9\%) ocorreram no fêmur, sendo uma no regerenado e outra no foco de correção das deformidades. Diferentemente do grupo submetido a alongamento, em todos esses casos foi necessária a confecção de um novo fixador externo circular. Também houve uma fratura da fíbula distal sem história de trauma, tratada conservadoramente.

Após a retirada do fixador, há relato de um paciente com gonartrose grave sintomática e outro com osteoartrite sintomática do tornozelo. Houve uma artrodese tibiotársica e uma artrodese de joelho durante o tratamento. Dois pacientes tiveram discrepância final mensurada, sendo de $3 \mathrm{~cm}$ e $3,7 \mathrm{~cm}$. Houve outro caso de discrepância nao especificada, mas com indicação futura de alongamento. Também houve um caso de deformidade em recurvatum e varo e outra não especificada.

A quantidade de abordagens cirúrgicas foi no total de 124 para os 22 pacientes, variando entre três e doze, tendo como média 5,63 abordagens e mediana de 5 . Os pacientes permaneceram internados por 1.511 dias, variando entre 5 e 183 dias, tendo como média 68,68 dias e mediana de 61,5 dias. 0 tempo total de uso do fixador externo foi de 550 meses completos, variando entre 8 e 55 meses, tendo como tempo médio 25 meses e mediana de 25,5 meses.

Vale citar que em apenas um caso não há registro de ter sido realizada revisão do foco da pseudartrose ou docking, sendo este o caso do transporte de motivo não informado.

\section{Discussão}

O atendimento na situação de urgência é crucial para a boa evolução dos casos. A remoção de toda a sujidade macroscópica e a instituição de antibioticoterapia agressiva pelo período apropriado está relacionada a menores índices de infecção e pseudartrose. ${ }^{13}$ Também foi vista a incapacidade da rede de hospitais de refêrencia em dar vazão aos casos que necessitam de fixador, tornando o tempo entre o trauma e a osteossíntese demasiadamente longo, o que gera angústia e sofrimento nos enfermos e prejudica o tratamento.

A montagem de fixador de Ilizarov para alongamento monofocal mostrou ser eficaz no tratamento das infecções e falhas ósseas de tamanho limitado no presente estudo, assim como observado por Iacobellis et al. ${ }^{9} \mathrm{O}$ menor tempo de uso do fixador externo, bem como de cirurgias por paciente e complicações nos faz optar por essa modalidade, sempre que as condições do membro permitem.

O transporte ósseo, apesar de eficiente, é de difícil execução, pois, além do maior número de complicações mostradas, depende mais ainda da capacidade intelectual e da cooperação do paciente. ${ }^{3}$

Uma rede multiprofissional orientada e apta a auxiliar na condução dos casos é crucial para reduzir ou limitar as complicações inerentes ao método. Dois dos casos de refratura ocorreram durante a prática fisioterápica, configurando uma intercorrência plenamente evitável.

Ocorreu a produção de grandes regenerados, tanto em tíbia proximal quanto em tíbia distal, com apenas um caso de refratura no regenerado da tíbia, cujo tamanho era de $2,5 \mathrm{~cm}$. Isso nos leva a pensar que, mais importante que o tamanho do regenerado em si, as refraturas são causadas pelo não seguimento das orientações após a retirada e o não utilização do tutor. 

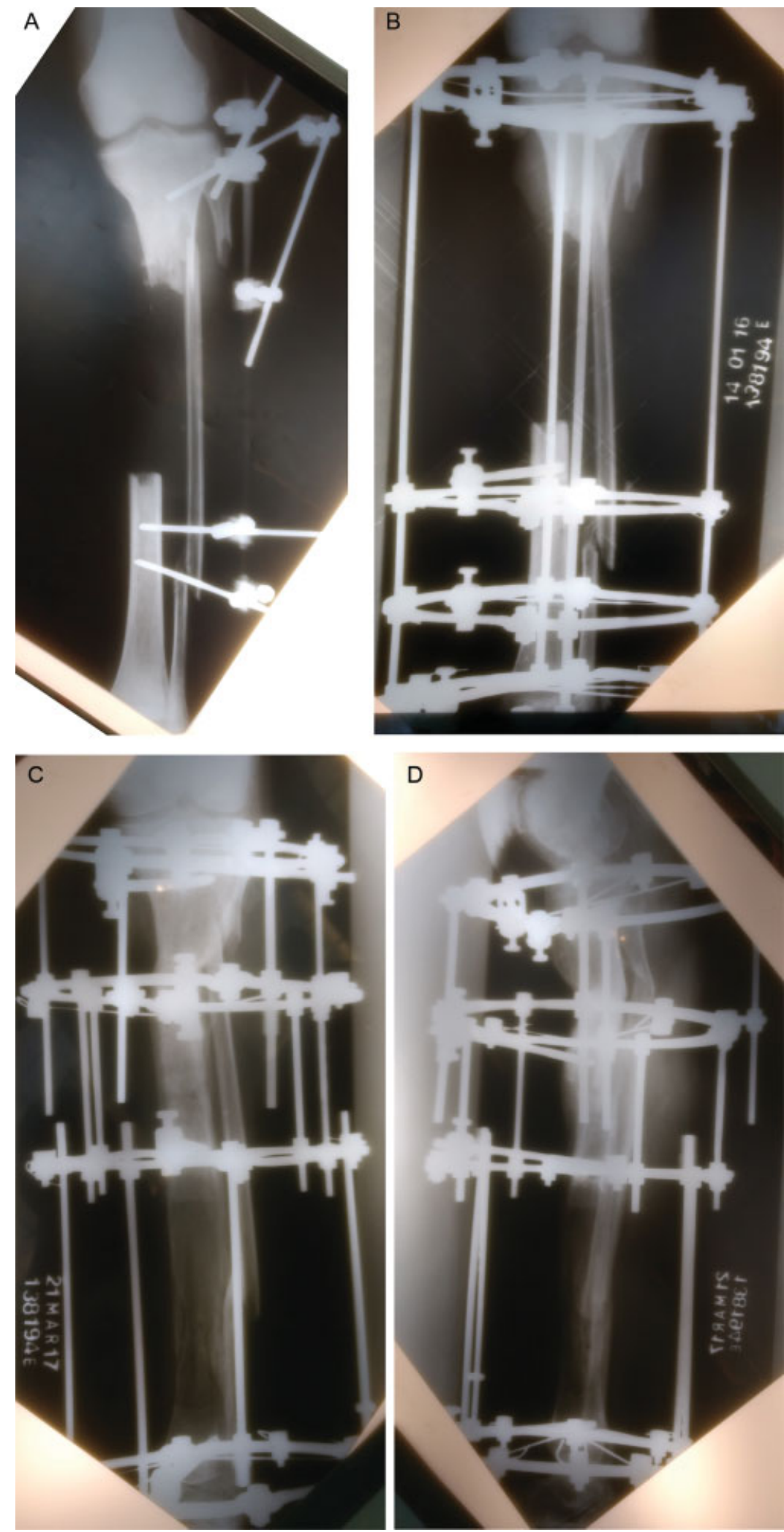

Fig. 1 Paciente 9, sexo masculino, 30 anos, submetido a transporte in Tandem retrógrado devido a falha óssea aguda pós-traumática (A). Montagem do fixador (B). Foi obtido um regenerado distal de $12 \mathrm{~cm}$ e diafisário de $2,5 \mathrm{~cm}$. Os eixos foram restaurados tanto no AP (C) como no perfil (D).

Por outro lado, a maioria das refraturas ocorreram no foco do docking/pseudartrose. Diante disso, é de se pensar sobre os benefícios em se postergar um pouco mais a retirada dos fixadores.

\section{Conclusão}

Diante dos dados apresentados, é notório que a maioria dos acidentes envolvem acidentes de motocicletas em pacientes do 

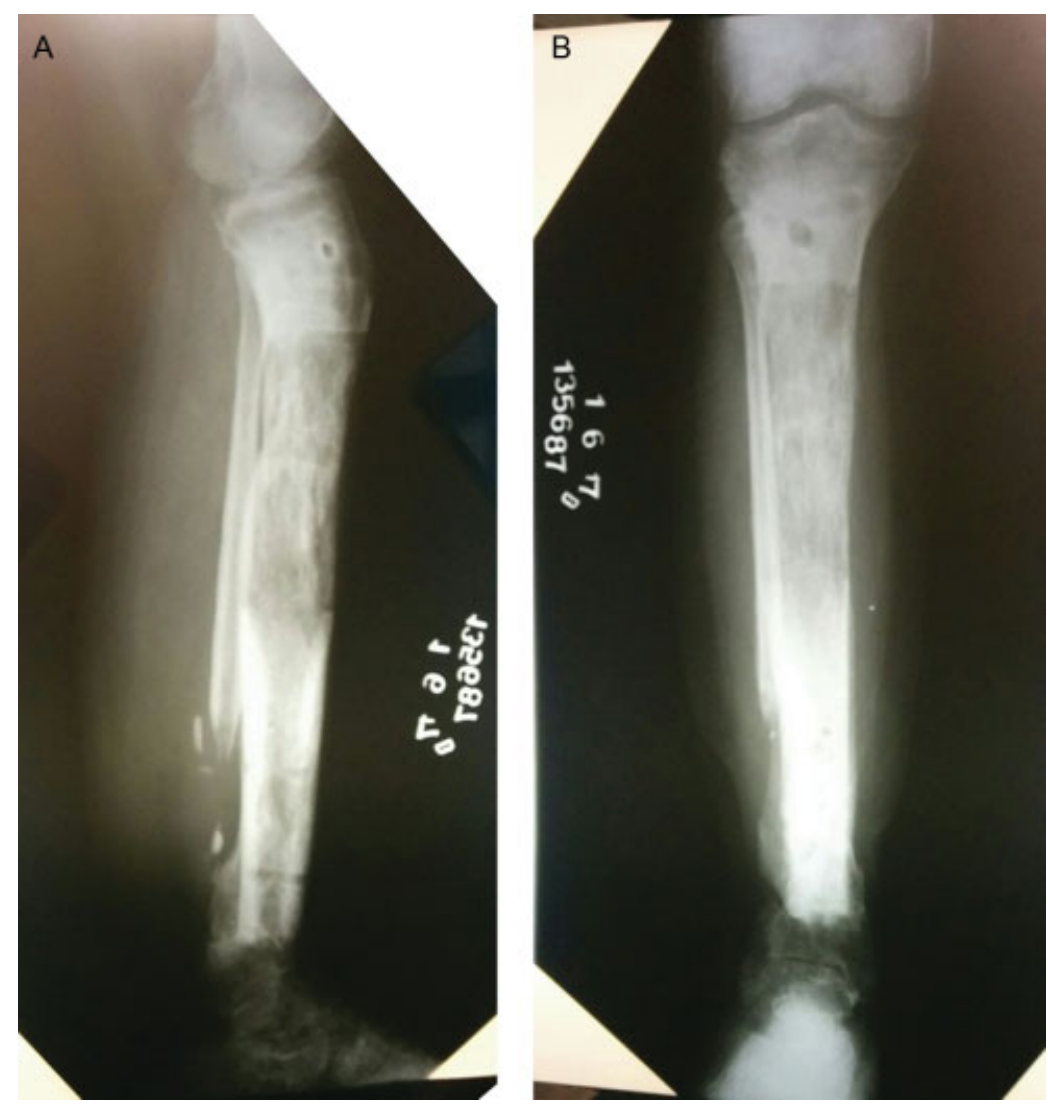

Fig. 2 Resultado final da paciente TMFM, 52 anos, que apresentava extensa área de osso inviável devido a pseudartrose infectada. Realizado transporte bifocal anterógrado. Renegerado final de $11,3 \mathrm{~cm}$.

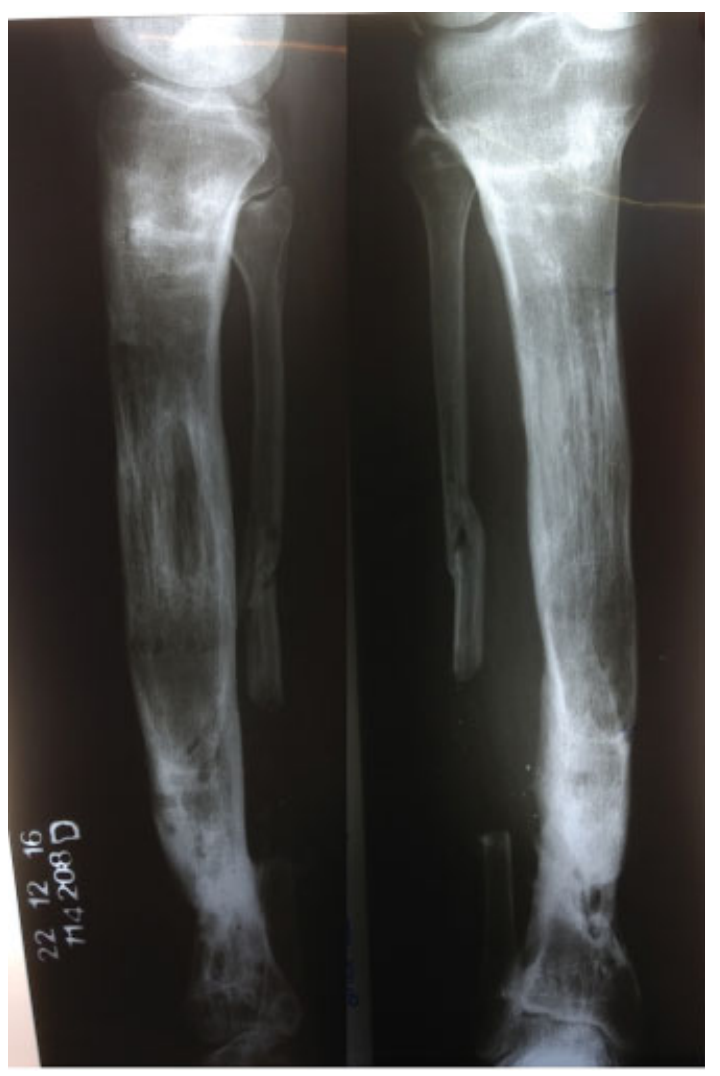

Fig. 3 Resultado final do paciente FNB, 34 anos, com regenerado em tíbia proximal medindo $17 \mathrm{~cm}$ após falha óssea aguda pós-traumática.
Tabela 1 Transporte tricocal: tamanho dos regenerados produzidos e posição relativa ao foco de compressão na tíbia

\begin{tabular}{|l|l|l|l|}
\hline Paciente & $\begin{array}{l}\text { Foco } \\
\text { proximal }\end{array}$ & $\begin{array}{l}\text { Foco } \\
\text { intermediário }\end{array}$ & Foco distal \\
\hline 01 & $6,0 \mathrm{~cm}$ & compressão & $1,5 \mathrm{~cm}$ \\
\hline 02 & $3,0 \mathrm{~cm}$ & compressão & $4,5 \mathrm{~cm}$ \\
\hline 03 & $4,0 \mathrm{~cm}$ & compressão & $9,5 \mathrm{~cm}$ \\
\hline 04 & $7,0 \mathrm{~cm}$ & compressão & $7,0 \mathrm{~cm}$ \\
\hline 05 & $4,5 \mathrm{~cm}$ & $1,2 \mathrm{~cm}$ & compressão \\
\hline 06 & $2,5 \mathrm{~cm}$ & $7,0 \mathrm{~cm}$ & compressão \\
\hline 07 & $3,2 \mathrm{~cm}$ & $4,0 \mathrm{~cm}$ & compressão \\
\hline 08 & $5,0 \mathrm{~cm}$ & $2,5 \mathrm{~cm}$ & compressão \\
\hline 09 & compressão & $2,5 \mathrm{~cm}$ & $12,0 \mathrm{~cm}$ \\
\hline 10 & compressão & $3,8 \mathrm{~cm}$ & $3,0 \mathrm{~cm}$ \\
\hline
\end{tabular}

sexo masculino e em idade economicamente ativa, gerando um grande prejuízo pessoal, social e previdenciário. Esse dado nos ajuda a guiar políticas públicas de prevenção de agravos.

Pacientes mal nutridos, fumantes, sem apoio familiar, ou com baixo nível intelectual são um fator de risco para o insucesso do tratamento devido a necessidade de reabordagens múltiplas em bloco cirúrgico, uso prolongado de medicamentos e correções no aparelho. Poderia ser optado pela amputação como forma de tratamento em pacientes não colaborativos 
ou naqueles que preferem esse método como forma de abreviar o longo tratamento e iniciar mais precocemente a sua reabilitação.

Por fim, a qualidade do preenchimento dos prontuários é sofrível, o que prejudicou a análise das informações e provavelmente o tratamento dos pacientes.

\section{Conflito de Interesses}

Os autores declaram não haver conflito de interesses.

\section{Referências}

1 Silva WN, Martins LH, Coutinho EC. Transporte ósseo da tíbia com o método de Ilizarov nos casos de pseudartrose com falha óssea. Rev Bras Ortop 1998;33(10):805-810

2 Tuffi GJ, Franco Filho N, Sbruzzi FC. Tratamento das infecções ósseas pelo método de Ilizarov usando o transporte ósseo e/ou a osteossíntese monofocal. Rev Bras Ortop 1997;32(08):583-590

3 Catagni MA, Guerreschi F, Lovisetti L, Camagni M. Ricostruzioni diafisarie con apparato di Ilizarov. GIOT 2005;31(Suppl 2):464-469

4 Papineau LJ, Alfageme A, Dalcourt JP, Pilon L. Chronic osteomyelitis: open excision and grafting after saucerization (author's transl). Int Orthop 1979;3(03):165-176
5 Neves J, Carvalho M, Araújo A, et al. Método de Papineau uma opção válida no tratamento da osteomielite e/ou pseudartrose infetada. Rev Port Ortop Traumatol 2014;22(04):431-438

6 Masquelet AC. Muscle reconstruction in reconstructive surgery: soft tissue repair and long bone reconstruction. Langenbecks Arch Surg 2003;388(05):344-346

7 Durigan A Junior, Batista LC. Corticotomia. Rev Bras Ortop 1997; 32(08):623-629

8 Li R, Saleh M, Yang L, Coulton L. Radiographic classification of osteogenesis during bone distraction. J Orthop Res 2006;24(03): 339-347

9 Iacobellis C, Berizzi A, Aldegheri R. Bone transport using the Ilizarov method: a review of complications in 100 consecutive cases. Strateg Trauma Limb Reconstr 2010;5(01):17-22

10 Mercadante MT, Santin RAL. Tratamento da pseudartrose da tíbia com falha óssea pelo método de Ilizarov. Rev Bras Ortop 1997;32 (08):591-599

11 Mercadante MT, Santin RAL, Ferreira RC. Análise crítica das técnicas cirúrgicas para artrodese do tornozelo. Rev Bras Ortop 2000;35(06):187-193

12 Catagni MA, Felici JVN. Alongamento de dois níveis e o método de Ilizarov (trifocal) no tratamento da pseudartrose tibial com perda óssea. Rev Bras Ortop 1996;31(08):613-619

13 Patzakis MJ, Wilkins J. Factors influencing infection rate in open fracture wounds. Clin Orthop Relat Res 1989;(243):36-40 